\title{
Wegener's granulomatosis mimicking inflammatory bowel disease and presenting with chronic enteritis
}

This article was published in the following Dove Press journal:

International Medical Case Reports Journal

4 October 2013

Number of times this article has been viewed

\author{
Kamyar Shahedi ${ }^{1,2}$ \\ Ramy Magdy Hanna ${ }^{1,2}$ \\ Oleg Melamed ${ }^{1,2}$ \\ James Wilson ${ }^{2,3}$ \\ 'Department of Medicine Olive-View \\ UCLA Medical Center, Sylmar, CA, \\ ${ }^{2}$ David Geffen School of Medicine \\ at UCLA, Los Angeles, CA, ${ }^{3} \mathrm{UCLA}$ \\ Medical Center-UCLA Stone Center, \\ Los Angeles, CA, USA
}

\begin{abstract}
Wegener's granulomatosis, also known as anti-neutrophil cytoplasmic antibody (ANCA)-associated vasculitis, is a small vessel vasculitis with primarily pulmonary, renal, and sinus disease manifestations. The prevalence of Wegener's granulomatosis is three cases per 100,000 patients. Cardiovascular, neurologic, cutaneous, and joint manifestations have been reported in many case reports and case series. Gastrointestinal manifestations are less noted in Wegener's granulomatosis, although they have been previously reported in the form of intestinal perforation and intestinal ischemia. Additionally, there are characteristic findings of vasculitis that are noted with active Wegener's granulomatosis of the small bowel. We report a case of an elderly patient who presented with weight loss, diarrhea, and hematochezia. His symptoms were chronic and had lasted for more than 1 year before diagnosis. Inflammatory bowel disease or chronic enteritis due to Salmonella arizonae because of reptile exposure originally were suspected as etiologies of his presentation. The findings of proteinuria, renal failure, and pauci-immune glomerulonephritis on renal biopsy, in conjunction with an elevated c-ANCA titer, confirmed the diagnosis of Wegener's granulomatosis with associated intestinal vasculitis. This case demonstrates an atypical presentation of chronic duodenitis and jejunitis secondary to Wegener's granulomatosis, which mimicked inflammatory bowel disease.
\end{abstract}

Keywords: ANCA-associated vasculitis, Wegener's syndrome, pauci-immune glomerulonephritis, Salmonella arizonae, inflammatory bowel disease

\section{Introduction}

Wegener's granulomatosis, also known as anti-neutrophil cytoplasmic antibody (ANCA)-associated vasculitis, is a vasculitis of the small arteries of the body. It is a rare disease, with a prevalence rate of three per 100,000 in the United States according to a 1996 epidemiologic study. ${ }^{1}$ Wegener's granulomatosis can present with multiple pulmonary and renal lesions, including cavitary lung lesions, fibrosis, and a rapidly progressive crescentic glomerulonephritis of the kidney. ${ }^{2-4}$ There are many other reported manifestations of Wegener's granulomatosis including cerebral vasculitis, ${ }^{5}$ cutaneous lesions, ${ }^{6}$ and otitis media. ${ }^{7}$ There are many case reports of cardiac conduction abnormalities, pulmonary hypertension, pericarditis, valvular disease, and other forms of cardiac manifestations of ANCA-associated vasculitis. ${ }^{8}$ The American College of Rheumatology's criteria for diagnosing Wegener's granulomatosis are clinical and do not require positive c-ANCA serology, although this test is generally helpful. The criteria include abnormal urinary sediment, abnormal findings on chest radiography, oral ulcers or nasal discharge, and granulomatous inflammation on biopsy. ${ }^{9}$
Correspondence: Ramy Magdy Hanna Department of Medicine Olive-View UCLA Medical Center, I4445 Olive View Drive, Sylmar, CA 91342, USA

Tel +l 8183643205

Email rhannamd8I@yahoo.com 
Gastrointestinal manifestations are unusual in Wegener's granulomatosis; however, several manifestations have been reported in the literature, including esophageal, small bowel, and colonic lesions. ${ }^{10-25}$ One of the more common manifestations of Wegener's vasculitis is intestinal perforation, likely due to bowel ischemia from severe vasculitis. There have been four case reports in the medical and surgical literature regarding small bowel perforation secondary to Wegener's granulomatosis. ${ }^{11,12,20,25}$ One case of bowel perforation occurred in c-ANCA-negative Wegener's granulomatosis. ${ }^{14}$ In one series, the prevalence of bowel perforation in 62 patients with systemic vasculitides including Wegener's granulomatosis was $15 \%$. Among those patients with bowel perforation, $16 \%$ also had bowel infarction and the observed mortality rate was $62 \% .^{6}$

Other manifestations of Wegener's granulomatosis in the gastrointestinal tract include spontaneous gastrointestinal bleeding, ${ }^{12,19}$ and esophageal strictures presenting with odynophagia were reported in 2000 by Fallows et al. ${ }^{21}$ Jejunal stenosis was also reported in 1997 by Rabe et al, ${ }^{17}$ and intestinal ischemia after a ruptured aneurysm of the middle colic artery was reported in a patient with c-ANCApositive vasculitis. ${ }^{22}$ Most of these uncommon gastrointestinal manifestations reported in the literature are acute and often catastrophic. Pagnoux et al reported on surgical emergencies in patients with small-vessel and medium-vessel vasculitides, and noted extremely high mortality rates and depressed 5-year and 10-year survival rates post abdominal surgery in patients with necrotizing vasculitides such as Wegener's granulomatosis. ${ }^{6}$ In this report, we examine a more chronic and insidious presentation of gastrointestinal Wegener's granulomatosis that closely mimicked inflammatory bowel disease. An interesting side issue was the isolation of Salmonella arizonae in the patient's stool after exposure to a reptile.

\section{Case report}

A 57-year-old Ukranian male with a 45-year history of smoking but no other medical history presented in August 2008 complaining of months of intermittent abdominal pain, diarrhea, and a $40 \mathrm{lb}$ weight loss. His symptoms presented over the course of 1 year. His diarrhea was initially evaluated and attributed to gastroenteritis. Routine studies were sent, including a stool culture. S. arizonae (subtype III), which is associated with osteomyelitis and gastroenteritis in reptile handlers, ${ }^{26}$ was isolated and the patient reported contact with a pet iguana. Computed tomography of the abdomen and pelvis was ordered and revealed a $1.5 \times 1.7 \mathrm{~cm}$ spiculated pulmonary nodule in the right upper lobe and thickening of the duodenal, jejunal, and colonic wall with scattered surrounding lymphadenopathy.

The patient was placed on antibiotics and continued to suffer from continued diarrhea and weight loss, so inflammatory bowel disease was suspected. In September 2008 he underwent endoscopic studies which revealed a hiatal hernia, old blood in the stomach, mucosal swelling near the gastric antrum, and three areas of circumferential ulceration and inflammation with mucosal pigmentation/erythema (see Figure 1). The areas were biopsied, and the biopsy showed reported duodenitis and jejunitis with acute on chronic inflammation. There were no signs of architectural distortion or cryptitis/crypt abscesses, Helicobacter pylori stains were negative, and no bacteria were apparent on biopsy. Given that

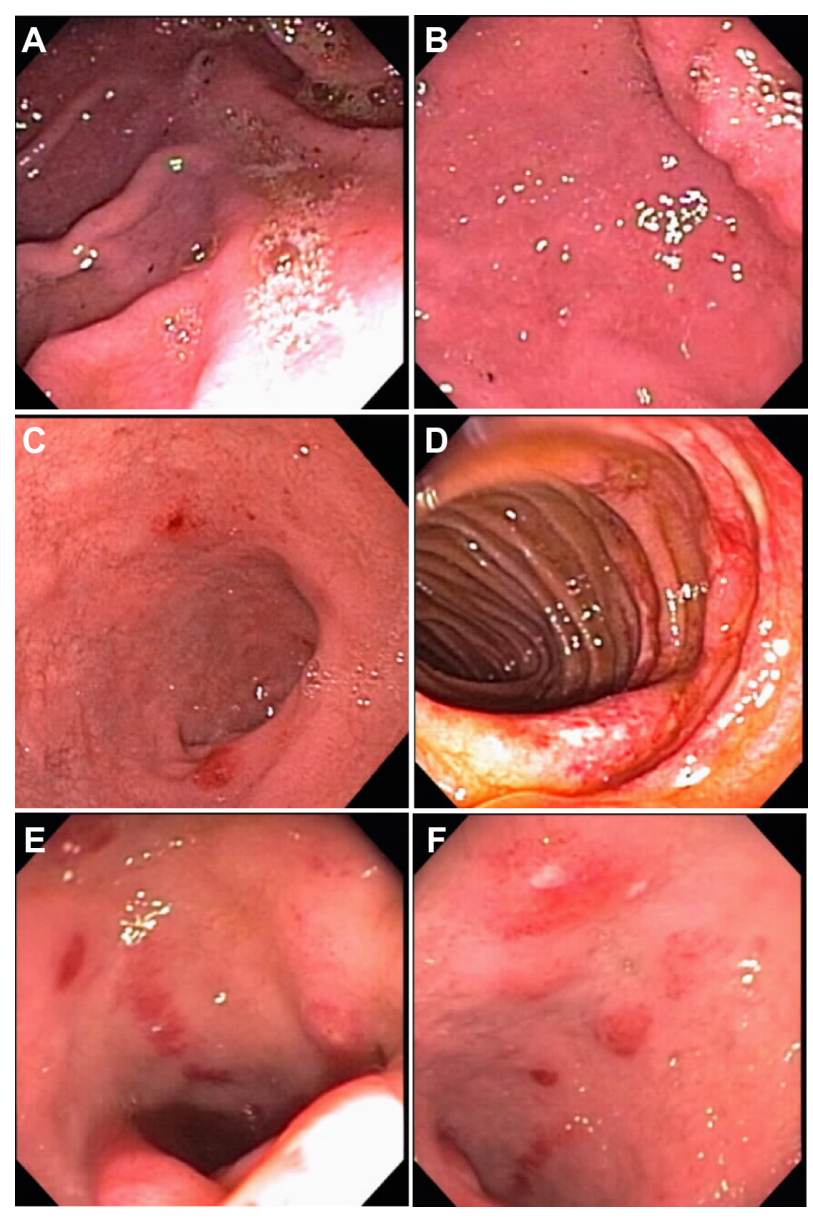

Figure I Multiple images from EGD procedures. (A) EGD image from September 2008 showing a normal gastric antrum. (B) EGD image from September 2008 showing mucosal swelling near the gastric antrum. (C) EGD image showing three discrete patches of inflammation in the duodenum. (D) EGD image from September 2008 showing inflammation and ulceration in the jejunum. (E) EGD image from November 2008 showing inflammation, hyperpigmented mucosa, and erythematous mucosa in the duodenum. (F) EGD image from November 2008 again showing duodenitis.

Abbreviation: EGD, esophagogastroduodenoscopy. 
the biopsies did not show any findings consistent with the suspected diagnosis of inflammatory bowel disease, his symptoms were attributed to $S$. arizonae gastroenteritis.

Fine needle aspiration of his pulmonary nodule was nondiagnostic, showing only clustered atypical epithelial cells. A positron emission tomography scan was obtained and showed a focus of hypermetabolic activity in the right upper lobe which was read as probable granulomatous disease.

He continued to have recurrent episodes of abdominal pain and vomiting in November 2008, and treatment of the presumptive $S$. arizonae gastritis/enteritis with trimethoprimsulfamethoxazole and ciprofloxacin failed to improve his symptoms. $S$. arizonae was not grown from stool samples that were resent.

One month later, the patient presented with back pain and decreased urine output. Acute kidney injury was noted, with a serum creatinine of $4.37 \mathrm{mg} / \mathrm{dL}$, while urine studies revealed severe proteinuria and hematuria. Initially the acute kidney injury was thought to be secondary to prerenal azotemia from dehydration or acute interstitial nephritis secondary to treatment with ciprofloxacin and trimethoprim-sulfamethoxazole. A c-ANCA level was drawn for workup of his renal failure and came back at $>100 \mathrm{U} / \mathrm{L}$. He then underwent repeat endoscopy which showed normal gastric mucosa, but granular and unusually pigmented duodenal mucosa (Figure 1). Biopsies of multiple sites were obtained, which later came back positive only in the ascending colon, which showed a tubular adenoma. Slides from a macroscopic jejunal ulcer seen on endoscopy (Figure 2) showed inflammation but no

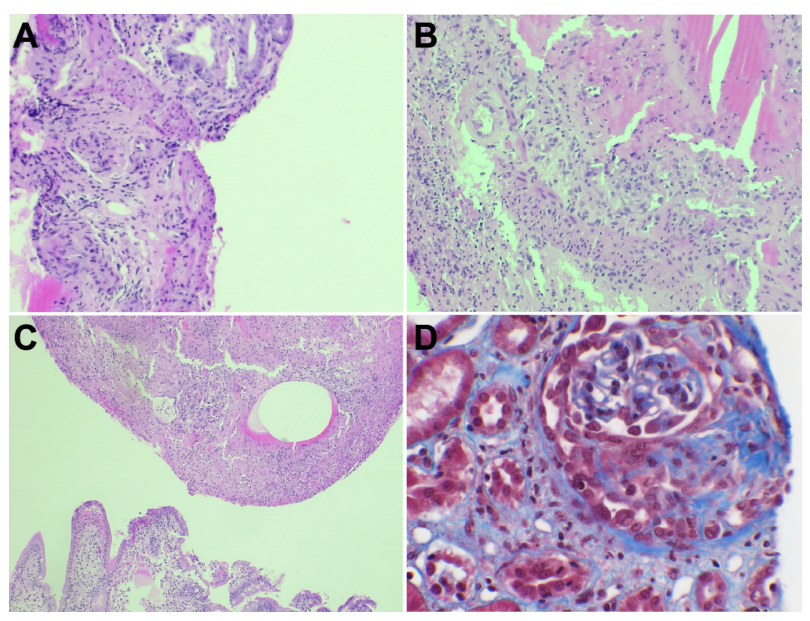

Figure 2 Hematoxylin and eosin stains of mucosal biopsies from esophagogastroduodenoscopy and trichrome stain of renal biopsy showing pauciimmune crescentic glomerulonephritis. (A-C) Multiple slides of jejunal mucosal ulcer with nonspecific inflammatory infiltrate without any bacteria, cryptitis, crypt abscesses, or evidence of vasculitis. (D) Trichrome stain from renal biopsy specimen showing a fibrocellular crescent consistent with rapidly progressive crescentic antineutrophil cytoplasmic antibody-positive-associated glomerulonephritis. features typical of inflammatory bowel disease. Given the unexplained nature of his systemic symptoms, acute kidney injury, and the positive c-ANCA, a kidney biopsy was performed and showed rapidly progressive glomerulonephritis due to pauci-immune crescentic glomerulonephritis with $25 \%$ crescents (Figure 2).

This renal biopsy result was clearly consistent with an ANCA-associated lesion, and the patient received three doses of cyclophosphamide between February and April 2009. Given the finding of a pulmonary nodule, video-assisted thoracoscopic surgery was performed in June 2009. The pathology results later came back positive for adenocarcinoma with clear margins. The lesion was surgically excised and a subsequent positron emission tomography scan was found to be negative for metastasis. He resumed cyclophosphamide therapy in December of 2009 and has had significant improvement of his gastrointestinal symptoms, renal impairment, and systemic symptoms on steroid and immunosuppressive therapy.

\section{Discussion}

While inflammatory bowel disease commonly occurs in middle-aged patients and can present in a manner very similar to the patient presented in the above report, it was not the underlying pathological process in this case. S. arizonae, which was also isolated in this case, is associated with exposure to reptiles and birds, ${ }^{26}$ and has been associated with bone infection, ${ }^{27}$ as well as joint infection, sepsis, ${ }^{28,29}$ and gastroenteritis. ${ }^{30}$ Rattlesnake products, such as rattlesnake venom pills ingested by cancer patients as a homeopathic remedy, have also been associated with infection due to this strain of bacteria. ${ }^{31}$ Patients infected with $S$. arizonae are usually immune-compromised secondary to young age, malignancy, or human immunodeficiency syndrome..$^{31-35}$ Ultimately, it turned out to be a very interesting finding that was probably unassociated with the patient's pathology.

The renal biopsy in particular was helpful because, unlike endoscopic biopsies, it was able to demonstrate the vasculitis adequately on histologic examination. While inflammatory bowel disease can often be diagnosed using endoscopic mucosal biopsies, vasculitides like Wegener's granulomatosis are often not well demonstrated on biopsy of the gastrointestinal tract since these biopsies are too superficial to visualize the intestinal arterioles.

The pigmentation of the duodenum and jejunum and the chronic inflammation seen were helpful clues that a vasculitis was present. The macroscopic pigmented appearance of the mucosa in the duodenum and jejunum predicted microscopic 
vasculitis, as was reported by Singhal et al in 2007. ${ }^{15}$ This unusual presentation of Wegener's granulomatosis in the small bowel details the need for increased clinical suspicion to diagnose vasculitis in the appropriate setting. The difficulty in making the diagnosis of Wegener's granulomatosis from mucosal biopsies was highlighted because ultimately a renal biopsy was needed to confirm the vasculitic process.

\section{Disclosure}

The authors report no conflicts of interest in this work.

\section{References}

1. Cotch MF, Hoffman GS, Yerg DE, Kaufman GI, Targonski P, Kaslow RA. The epidemiology of Wegener's granulomatosis. Estimates of the five-year period prevalence, annual mortality, and geographic disease distribution from population-based data sources. Arthritis Rheum. 1996;39(1):87-92.

2. Launay D, Souza R, Guillevin L, et al. Pulmonary arterial hypertension in ANCA-associated vasculitis. Sarcoidosis Vasc Diffuse Lung Dis. 2006;23(3):223-228.

3. Ketata W, Msaad S, Gharsalli H, et al. Pulmonary fibrosis as a presentation of Wegener's granulomatosis. Rev Mal Respir. 2009;26(9): 981-984. French.

4. John R, Herzenberg AM. Vasculitis affecting the kidney. Semin Diagn Pathol. 2009;26(2):89-102.

5. Nadeau SE. Neurologic manifestations of systemic vasculitis. Neurol Clin. 2002;20(1):123-150, vi.

6. Pagnoux C, Mahr A, Cohen P, Guillevin L. Presentation and outcome of gastrointestinal involvement in systemic necrotizing vasculitides: analysis of 62 patients with polyarteritis nodosa, microscopic polyangiitis, Wegener granulomatosis, Churg-Strauss syndrome, or rheumatoid arthritis-associated vasculitis. Medicine (Baltimore). 2005;84(2):115-128.

7. Shuto J, Suenaga S, Tateyama K, Oribe K, Suzuki M. Acute onset Wegener's granulomatosis presenting as otitis media; a case report. Nihon Jibiinkoka Gakkai Kaiho. 2007;110(3):107-110. Japanese.

8. Grant SC, Levy RD, Venning MC, Ward C, Brooks NH. Wegener's granulomatosis and the heart. Br Heart J. 1994;71(1):82-86.

9. Leavitt RY, Fauci AS, Bloch DA, et al. The American College of Rheumatology 1990 criteria for the classification of Wegener's granulomatosis. Arthritis Rheum. 1990;33(8):1101-1107.

10. Tupler RH, McCuskey WH. Wegener granulomatosis of the colon: CT and histologic correlation. J Comput Assist Tomogr. 1991;15(2): 314-316.

11. Tokuda M, Kurata N, Daikuhara H, et al. Small intestinal perforation in Wegener's granulomatosis. $J$ Rheumatol. 1989;16(4):547-549.

12. Strivens RL, Bateman A, Arden NK, Edwards CJ. Intestinal perforation and jejunal haemorrhage due to Wegener's granulomatosis. Clin Exp Rheumatol. 2005;23(1):124.

13. Storesund B, Gran JT, Koldingsnes W. Severe intestinal involvement in Wegener's granulomatosis: report of two cases and review of the literature. Br J Rheumatol. 1998;37(4):387-390.

14. Socas Macias M, Sanchez Bernal ML, Suarez Artacho G, et al. Severe intestinal involvement in Wegener's granulomatosis with negative c-ANCAs. Rev Esp Enferm Dig. 2005;97(9):670-671.
15. Singhal R, Goodyear S, Fraser I. Macroscopic appearance of the bowel predicts microscopic involvement in gastrointestinal Wegener's granulomatosis: a previously unreported sign. Minerva Chir. 2007;62(2):149.

16. Singh S, Sakhuja V, Rajwanshi A, Chugh KS. Gastrointestinal tract involvement in Wegener's granulomatosis. $J$ Assoc Physicians India. 1985;33(2):180-181.

17. Rabe J, Guckel F, Nowack R, et al. Jejunum stenosis as a late sequela of small-intestinal involvement in Wegener's granulomatosis. Rofo. 1997;166(4):358-360. German.

18. Pinkney JH, Clarke G, Fairclough PD. Gastrointestinal involvement in Wegener's granulomatosis. Gastrointest Endosc. 1991;37(3):411-412.

19. Horvath G, Horvath G, Kelemen T, David K. Fulminating course of Wegener's granulomatosis associated with gastrointestinal bleeding. Orv Hetil. 1989;130(27):1441-1445. Hungarian.

20. Geraghty J, Mackay IR, Smith DC. Intestinal perforation in Wegener's granulomatosis. Gut. 1986;27(4):450-451.

21. Fallows GA, Hamilton SF, Taylor DS, Reddy SB. Esophageal involvement in Wegener's granulomatosis: a case report and review of the literature. Can J Gastroenterol. 2000;14(5):449-451.

22. Dutton-Gaddis JG, Oyekan TB, Haraway GD, Crapse FJ. Middle colic artery rupture in a patient with ANCA associated vasculitis: a case report. J Okla State Med Assoc. 2004;97(9):364-366.

23. Deniz K, Ozseker HS, Balas S, Akpynar E, Sokmensuer C. Intestinal involvement in Wegener's granulomatosis. J Gastrointestin Liver Dis. 2007;16(3):329-331.

24. Chow FY, Hooke D, Kerr PG. Severe intestinal involvement in Wegener's granulomatosis. J Gastroenterol Hepatol. 2003;18(6):749-750.

25. Akca T, Colak T, Caglikulekci M, Ocal K, Aydin S. Intestinal perforation in Wegener's granulomatosis: a case report. Ulus Travma Derg. 2005;11(4):348-351. Turkish.

26. Hopkins KL, Peters TM, Lawson AJ, Owen RJ. Rapid identification of Salmonella enterica subsp. arizonae and S. enterica subsp. diarizonae by real-time polymerase chain reaction. Diagn Microbiol Infect Dis. 2009;64(4):452-454.

27. Ozdemir D, Sahin I, Sencan I. Salmonella arizonae bacteraemia in a Turkish patient with AIDS but no history of contact with reptiles. Scand J Infect Dis. 2006;38(3):237-238.

28. Schneider L, Ehlinger M, Stanchina C, et al. Salmonella enterica subsp. arizonae bone and joints sepsis. A case report and literature review. Orthop Traumatol Surg Res. 2009;95(3):237-242.

29. Nowinski RJ, Albert MC. Salmonella osteomyelitis secondary to iguana exposure. Clin Orthop Relat Res. 2000;(372):250-253.

30. Foster N, Kerr K. The snake in the grass - Salmonella arizonae gastroenteritis in a reptile handler. Acta Paediatr. 2005;94(8):1165-1166.

31. Sharma J, Von Hoff DD, Weiss GR. Salmonella arizonae peritonitis secondary to ingestion of rattlesnake capsules for gastric cancer. $J$ Clin Oncol. 1993;11(11):2288-2289.

32. Hoag JB, Sessler CN. A comprehensive review of disseminated Salmonella arizona infection with an illustrative case presentation. South Med J. 2005;98(11):1123-1129.

33. Mahajan RK, Khan SA, Chandel DS, Kumar N, Hans C, Chaudhry R. Fatal case of Salmonella enterica subsp. arizonae gastroenteritis in an infant with microcephaly. J Clin Microbiol. 2003;41(12):5830-5832.

34. Cortes E, Zuckerman MJ, Ho H. Recurrent Salmonella arizona infection after treatment for metastatic carcinoma. J Clin Gastroenterol. 1992;14(2):157-159.

35. Casner PR, Zuckerman MJ. Salmonella arizonae in patients with AIDS along the US-Mexican border. N Engl J Med. 1990;323(3):198-199. 
International Medical Case Reports Journal

Dovepress

\section{Publish your work in this journal}

The International Medical Case Reports Journal is an international, peer-reviewed open-access journal publishing original case reports from all medical specialties. Previously unpublished medical posters are also accepted relating to any area of clinical or preclinical science. Submissions should not normally exceed 2,000 words or

4 published pages including figures, diagrams and references. The manuscript management system is completely online and includes a very quick and fair peer-review system, which is all easy to use. Visit $\mathrm{http}: / / \mathrm{www}$.dovepress.com/testimonials.php to read real quotes from published authors.

Submit your manuscript here: http://www.dovepress.com/international-medical-case-reports-journal-journal 